\title{
Opportunities to Learn Three-Dimensional Shapes in Primary Mathematics: The Case of Content Analysis of Primary Mathematics Textbooks in Hong Kong
}

\author{
Qiaoping Zhang ${ }^{1^{*}}$ \\ ${ }^{1}$ Department of Mathematics and Information Technology, The Education University of Hong Kong, HONG KONG
}

Received 18 May 2020 - Accepted 24 February 2021

\begin{abstract}
Textbooks play an important part in teaching and learning mathematics. However, textbook research on spatial ability has so far received little attention. In this study, we investigated whether school mathematics textbooks provide enough opportunities for primary students to learn threedimensional shapes and help them acquire spatial ability. Three mathematics textbook series used in Hong Kong were analysed through content analysis. Findings showed each series of textbooks contained five domains for introducing solid figures, which included real-life examples, understanding concepts, measurement, finding laws, and developing spatial ability. The development of spatial abilities was mainly shown in the production of three-dimensional graphics. What students experienced in the learning of 3-D shapes was relatively narrow. Geometric graphics were mainly limited to the conventional shapes at the early stage. Activities to explore three-dimensional graphics were insufficient. It was suggested that combining the surrounding world of children with geometry in the classroom was not just a criterion for textbooks but also the focus of classroom teaching. The flexibility of teachers' adoptions of textbooks is also worthy of further investigation.
\end{abstract}

Keywords: opportunities to learn, three-dimensional shapes, spatial ability, primary mathematics textbooks, textbook analysis

\section{INTRODUCTION}

Developing students' spatial ability is an important objective of mathematics education. Positive correlations have been found between spatial ability and mathematics achievement at all grade levels (Clements \& Battisa, 1992, p. 443). Spatial ability has been not only linked to higher student achievement in mathematics (Mix and Cheng, 2012) but also other STEM disciplines (Wai, Lubinski, \& Benbow, 2009). In school curriculum, students mainly develop spatial skills within the learning area of space, shape and measures (Curriculum Development Council [CDC], 2002). Internationally, in the Programme for International Student Assessment (PISA), students' spatial ability which relates to their mathematical literacy involves "understanding perspectives, creating and reading maps, transforming shapes with and without technology, interpreting views of 3D scenes from various perspectives, and constructing representations of shapes" (OECD, 2019, p. 85).
However, it is not easy to help students acquire such ability, even for those students who have consistently achieved outstanding performances in international assessments in mathematics, including PISA and TIMMS. For instance, in HKPISA 2012 report, it was found that Hong Kong students' the percentage of correct answers in the contents of space and shape was the lowest comparing to other dimensions between PISA 2003, PISA 2006, PISA 2009 and PISA 2012 (Wong, 2014, p. 83). Comparing to other Eastern Asian economies (e.g., Japan, Korea and Singapore), Hong Kong students' overall performance in space and shape is also lowest (OECD, 2014, p. 113). It is of interest to know what kinds of learning opportunities that students received from school mathematics curriculum.

Research has reported that students usually had learning difficulties in 3-D shapes (Hallowell, Okamoto, Romo, \& La Joy, 2015; Kan, Ma, So, \& Wong, 1995, 1996; $\mathrm{Ng}$, Shi, \& Ting, 2020). As key learning and teaching material, school textbooks are regarded as one 


\section{Contribution to the literature}

- The study identified five aspects including real-life examples, understanding concepts, measurement, finding laws, and developing spatial ability to help students learn 3-D shapes in Hong Kong primary mathematics textbooks.

- Students' experiences in learning geometric graphics were relatively narrow and mainly focused on conventional shapes.

- More exploration activities of 3-D shapes shall be emphasised in textbooks and classroom teaching.

expression of the intended curriculum (Mesa, 2004). Many researches have pointed out a strong influence of textbooks on the mathematics content that is taught and learned. The instructional approach suggested by the curriculum materials often influences teachers' pedagogical strategies. Stein, Remillard, and Smith (2007, p. 327) argued that, "what mathematical topics are covered in a given set of curriculum materials is of fundamental importance". If mathematical topics are not included in textbooks, they are most likely not presented by the teachers. Teachers' teaching sequence is often parallel to that of textbooks (Freeman \& Porter, 1989; Reys et al., 2003). Thus, in this study, the main purposes of this study are aimed to investigate what kinds of learning opportunities that textbooks provide to primary students in learning; three-dimensional (3D) shapes. In particular, we will focus on below questions:

1. What do students learn about 3-D shapes from primary mathematics textbooks?

2. How are the relevant contents organised in their textbooks? What are the commonalities and difference among different textbooks in Hong Kong?

3. Do students receive enough opportunities to acquire spatial abilities through textbooks?

We also discuss the implications of such textbook analysis in advancing our understanding of the difficulties inherent to the teaching and learning of 3-D shapes. Before we describe how the textbook analysis was carried out and what results were achieved, we begin with literature review that guided the setup of our analysis.

\section{LITERATURE REVIEW}

\section{Spatial Ability in School Curriculum}

As an essential part of the school curriculum, geometry has its special role. Teaching geometry in the classroom is exactly to bridge the gap between the virtual (abstract) world and the real (concrete) world. Developing students' spatial ability is a main objective in school geometry education. Students' representation of space is not a perceptual "reading off" of the spatial environment but is built up from prior active manipulation of that environment (Clements \& Battisa, 1992). How then should the learning environment for students' spatial ability be shaped? In Lohman's (1988) definition, spatial ability is "the ability to generate, retain, retrieve, and transform well-structured visual images." This ability can be viewed as a unique type of intelligence distinguishable from other forms of intelligence, such as verbal ability, reasoning ability, and memory skills. In TIMMS 2011, spatial sense/ability is integral to the study and assessment of geometry. Students should use spatial visualisation skills to relate between two- and three-dimensional representations of the same shape. Specifically, at Grade 4, students will be asked to describe, visualise, and draw a variety of geometric figures, including angles, lines, triangles, quadrilaterals, and other polygons. Students should be able to make and decompose compound shapes of common geometric figures. They should be able to recognise line symmetry, draw symmetrical figures, and describe rotations (Mullis, Martin, Foy, \& Arora, 2012).

When teachers focus on mathematical definitions, concepts, signs, or properties, it might not be effective to help students to construct a spatial image and to manipulate it when trying to solve a problem in 3-D geometry. In a recent research, Abdullah, Ahmad, and Nohseth (2020) identified six types of difficulties faced by students in learning Shape and Space topics. The students have difficulties in: (1) recognizing the types of 2-D and 3-D shapes, (2) drawing the 2-D and 3-D shapes, (3) count the edge of the shapes, (4) identifying the types of straight, curved and the number of shape surfaces, (5) drawing the 3-D shape net, and (6) combining the basic shapes in a net. The main factor contributing to the difficulties lies in the visualization process and the abstract geometric basic knowledge. Specified on the spatial abilities in 3-D geometry, Ng, Shi, and Ting (2020) summarized that students always relied too much on the perceptual attributes of 3-D shapes and failed to decompose any shape into its basic elements and identify its properties. Students felt challenging in understanding the mental rotations and mental transformations of 3-D shapes.

How does one acquire spatial ability? Traditionally, critical features of spatial ability in science education (including mathematics) have been the skills required to construct efficient mental models of objects from verbal descriptions in textbooks or instruction. Although researchers are using teaching aids (Ping \& Hua, 2016), Augmented Reality (Flores-Bascuñana, Diago, VillenaTaranilla, \& Yáñez, 2020), 3D printing (Ng, Shi, \& Ting, 
Table 1. Shape and Space in the primary mathematics curriculum in Hong Kong

\begin{tabular}{|c|c|c|}
\hline & Key Stage 1 (P1-P3) & Key Stage 2 (P4-P6) \\
\hline $\begin{array}{l}\text { Learning } \\
\text { Targets }\end{array}$ & $\begin{array}{l}\text { - identify, describe and group 2-dimensional \& 3-dimensional shapes; } \\
\text { - recognize intuitively the elementary properties of 3-dimensional shapes; } \\
\text { - recognize the properties of 2-dimensional shapes; } \\
\text { - make 2-dimensional and } 3 \text { dimensional shapes from given information; } \\
\text { - recognize, describe and appreciate shapes; } \\
\text { - identify the four directions. }\end{array}$ & $\begin{array}{l}\text { - understand the properties of 2- } \\
\text { dimensional and 3-dimensional } \\
\text { shapes; } \\
\text { - group and make 2-dimensional and } \\
\text { 3-dimensional shapes; } \\
\text { - identify the eight compass points. }\end{array}$ \\
\hline $\begin{array}{l}\text { Learning } \\
\text { Units }\end{array}$ & $\begin{array}{l}\text { - 3-D shapes (I) (prisms, pyramids and spheres) } \\
\text { - } \text {-D shapes (II) (prisms, cylinders, pyramids and cones) } \\
\text { - Straight lines and curves } \\
\text { - 2-D shapes (polygons and circles) } \\
\text { - Quadrilaterals (I) (rectangles, squares, trapeziums, rhombuses, etc.) } \\
\text { - Triangles } \\
\text { - Angles (I) (angles and right angles) } \\
\text { - Angles (II) (acute and obtuse angles) } \\
\text { - The four directions } \\
\text { Parallel and perpendicular }\end{array}$ & $\begin{array}{l}\text { - Quadrilaterals (III) (characteristics } \\
\text { of quadrilaterals) } \\
\text { - Fitting and dissecting shapes } \\
\text { - Symmetry } \\
\text { - The eight compass points } \\
\text { - 3-D shapes (III) (characteristics of } \\
\text { prisms, pyramids and spheres) } \\
\text { - 3-D shapes (IV) (vertices, edges, } \\
\text { faces and sections) } \\
\text { - Circles }\end{array}$ \\
\hline
\end{tabular}

2020) to help student learn 3D shapes, geometry textbooks are likely to offer more benefits to improve students' spatial skills than other resources, which are important determinants of what children are taught and what they learn at school. Internationally, on average, textbooks are used most often as the basis for mathematics instruction, for $75 \%$ of Grade 4 students and $77 \%$ of Grade 8 students (Mullis, Martin, Foy, \& Arora, 2012, p. 391). In TIMMS 2007, internationally, 65\% of Grade 4 mathematics teachers use textbooks as the primary teaching material, and $30 \%$ use it as a supplement. These numbers in Hong Kong are noticeably higher: $84 \%$ and $15 \%$ respectively (Mullis, Martin, \& Foy, 2008, p. 290). Recently, in TIMMS 2011, the percentage of Hong Kong Grade 4 mathematics teachers who used textbooks as a basis for instruction reached $88 \%$, whilst the percentage of teachers who used textbooks as supplementary resources was 11\% (Mullis, Martin, Foy, \& Arora, 2012, p. 392-394). Thus, textbooks are the main sources for teachers' instruction. If we want to know how primary students learn 3-D shapes, we need to know how the contents of spatial geometry are presented in their textbooks. In particular, do the contents provide sufficient active manipulations/activities or opportunities for students to acquire spatial ability? In the following section, we will describe the Shape and Space topics in Hong Kong's mathematics textbooks.

\section{Shape and Space in Primary Mathematics Textbooks in Hong Kong}

In Hong Kong primary mathematics curriculum, learning spatial skills or developing spatial ability belongs to the second dimension - Shape and Space (Table 1 provides the details (CDC, 2000, p. 14-48). Examples on the organisation of the units covering spatial geometry (include the $3-\mathrm{D}$ shapes and measurement of Volume) can be found in Appendix 1.

\section{Opportunity to Learn and the Role of Textbook Analysis}

Reys, Reys, Lapan, Holliday, and Wasman (2003) pointed out that teachers' pedagogical strategies were often influenced by the instructional approach of the material. Their sequences of instruction were often parallel to that of the textbooks. Even textbooks follow the same curriculum standard, they still have many differences. Stein, Remillard, and Smith (2007) found that there were great differences between two mathematics textbooks in the United States. These differences included what content was covered, how the content was presented, including order, balance and organisation, which would influence students' achievements in mathematics. How topics are presented in the text is important because it sets in motion "pedagogical approaches and different opportunities for students' learning" (Stein et al., 2007, p. 327). Textbooks covered the main content used in classrooms, which are regarded to determine largely the degree of students' opportunity to learn (Wijaya, van Den HeuvelPanhuizen, \& Doorman, 2015). They not only provide a framework for teachers to plan what will be taught, how they teach, and what homework or activities are assigned to students (Nicol \& Crespo, 2006), but to also influence the output of teaching (Haggarty \& Pepin, 2002), and provide indications of students' opportunities to learn (Tornroos, 2005). If mathematical topics not included in textbooks, they were most likely not presented by the teachers.

In the UNESCO guidebook of textbook analysis, Pingel (1999) proposed an important concern of textbook research: the content of 'the text itself'. In other words, what is included in the text, what is omitted and why. These are closely related to students' learning opportunities. In the research of mathematics textbook analysis, some studies have also focused on the mathematical problems in mathematics textbooks, including exercises and problems that the books 
provided for students (Vincent \& Stacey, 2008), nonroutine problems (Kolovou, Heuvel-Panhuizen, \& Bakker, 2009), variation problems (Sun, 2011), representation of problem and problem-solving procedures (Fan \& Zhu, 2007). For instance, compared with mainland China, Fan, and Zhu (2007) found U.S. textbooks introduced problem-solving heuristics more explicitly. Some researchers also focused on specific topics of the mathematics curriculum, such as computation (Carter, Li, \& Ferrucci, 1997; Reys, Reys, \& Koyama, 1996), fractions (Alajmi, 2012; Charalambous, Delaney, Hsu, \& Mesa, 2010; Sun, 2011), function (Mesa, 2004), and probability (Jones \& Tarr, 2007). However, empirical studies of textbook analysis in spatial geometry are little discussed. In particular, only a few papers have investigated geometry textbooks in Hong Kong. By the use of content analysis, Hsu's research team (Hsu \& Hsu, 2009; Hsu \& Lin, 2007) compared algebra and geometry material in elementary school textbooks between Taiwan and Hong Kong. In algebra, both regions emphasised the concepts of 'building basic algebra concepts' and 'understanding and applying symbols of unknown quantity'. The differences were that Taiwan adopted a spiral method and integrated with the number as a unit, whereas Hong Kong adopted a thematic method and presented an independent unit of algebra. As for geometry, compared with Taiwan, Hong Kong's textbooks emphasised more real-life application and contained wider and deeper geometry materials. Taiwan's textbooks had more open questions and were mostly represented with practical pictures than Hong Kong's. The presentations of materials in the two regions both lacked the concept of space. In another study, Kan, Ma, So, and Wong $(1995,1996)$ analysed the Shape and Space dimension of two primary school textbooks in Hong Kong. It was found that the development of spatial sense was dominated by stereotyped techniques and lacked specific activities, most of which were out of the reach of students at that developmental stage. Examples used in the textbooks were mostly typical and diversity to cater for individual differences was lacking.

Since 2000, like many other places around the world, Hong Kong launched a new mathematics reform (Wong, Han, \& Lee, 2004). To cater for students' diversity, teachers are encouraged to organize "diversified learning activities to arouse students' interests and develop their mathematical abilities. Learning and teaching should be closely related to students' hands-on experiences ... Apart from solving routine problems which involve mostly rote learning, more emphases should be put on exploratory activities which involve diversified thinking abilities" (CDC, 2002, p. 32). To some extent, the contents and organization of textbooks reflected the ideas and objectives of new curriculum syllabus. Thus, it is worthy to know how are the contents of spatial geometry presented in textbooks under the reform? Do these contents provide enough opportunities for students to learn geometry to caster for individual difference and acquire spatial ability? In this study, we will use the content analysis to investigate how 3-D geometry is presented in primary school textbooks in Hong Kong and what the learning opportunities provided to students.

\section{METHODOLOGY}

\section{Textbook Sampling}

In Hong Kong, schools may use textbooks and learning materials on the recommended textbook list by the Education Bureau (EDB). Contents of textbooks should be written in line with syllabuses/curriculum guides/curriculum and assessment guides issued by the CDC, which should reflect the curriculum aims and expected learning outcomes of students, and contain the core elements of the curriculum. In the textbook market, there are, in print, eight series of mathematics textbooks for lower primary level (Grades 1-3) and nine for upper primary level (Grades 4-6). In the study, we included three series of textbooks that are currently widely used in Hong Kong primary schools. They are: 21st Century Modern Mathematics (Modern), Oxford University Press (Oxford), and Longman New Century (Longman). All of them are based on the CDC curriculum guide (2002). Table 2 shows a detailed overview of the primary textbooks selected for the study.

\section{Content Analysis}

In order to know the structure and content of spatial geometry in the textbooks, we used the content analysis method. Content analysis has been defined as a systematic, replicable technique for compressing many words of text into fewer content categories based on explicit rules of coding (Krippendorff, 1980). The coding process followed the ideas of grounded theory by Strauss and Corbin (1990). According to van Hiele (1986), primary students' geometric thinking usually experienced several levels which include recognizing the shapes, classifying the shapes, naming the properties of shapes, and perceiving relationship among properties. These levels are used for establishing categories in the process of analysing the data. Each highlighted section in the textbooks was categorised according to the kind of block it belonged to.

\section{RESULTS AND DISCUSSION}

Through the comparison, it was shown that these three sets of textbooks included the learning content in the mathematics curriculum. However, there were many different learning objectives involved in the topic, which were presented in different approaches. These objectives included real-life examples, concepts of 3-D shapes, measures, laws of 3-D shapes and spatial ability. When 
Table 2. Textbook series documents included in the textbook analysis

\begin{tabular}{|c|c|c|}
\hline Publisher & Textbook series & Unit \\
\hline \multirow[t]{6}{*}{ Modern } & $1 \mathrm{~A}$ & Chapter 11 3-D Shapes (I) \\
\hline & $5 \mathrm{~A}$ & $\begin{array}{l}\text { Chapter } 43 \text {-D Shapes (II) } \\
\text { Chapter } 53 \text {-D Shapes (III) }\end{array}$ \\
\hline & $5 B$ & $\begin{array}{l}\text { Chapter } 17 \text { recognize volume } \\
\text { Chapter } 18 \text { measure the volume of objects } \\
\text { Chapter } 19 \text { the volume of cubes and cuboids }\end{array}$ \\
\hline & $6 \mathrm{~A}$ & $\begin{array}{l}\text { Chapter } 4 \text { 3-D Shape (IV) } \\
\text { Chapter } 5 \text { 3-D Shape (IV) }\end{array}$ \\
\hline & $6 \mathrm{~B}$ & $\begin{array}{l}\text { Chapter } 15 \text { capacity and volume } \\
\text { Chapter } 16 \text { the volume of irregular solids } \\
\text { Chapter } 17 \text { Section of 3-D shapes }\end{array}$ \\
\hline & 6B Enrichment & Chapter 21 make pyramids \\
\hline \multirow[t]{5}{*}{ Longman } & $1 \mathrm{~A}$ & 3-D Shaper (I) \\
\hline & $2 \mathrm{~B}$ & 3-D Shaper (II) \\
\hline & $5 \mathrm{D}$ & 3-D Shaper (III); Volume (I) \\
\hline & $6 \mathrm{~A}$ & 3-D Shapes (IV); Enrichment \\
\hline & $6 \mathrm{~B}$ & Volume (II) \\
\hline \multirow[t]{4}{*}{ Oxford } & 1 & Unit4 3-D Shapes (I) \\
\hline & 2 & Unit 4 3-D Shapes (II) \\
\hline & 5 & Unit 4 3-D Shape (III); Unit 11 Volume (I) \\
\hline & 6 & Unit 3 3-D Shape (IV); Unit 4 Volume (II) \\
\hline
\end{tabular}

\begin{tabular}{|c|c|c|}
\hline $\begin{array}{l}\text { Grade 1 } \\
\text { Introduce 3-D } \\
\text { shapes through } \\
\text { daily life } \\
\text { examples } \\
\text { Characteristics: } \\
\text { shaped size } \\
\text { Focus on prisms, } \\
\text { pyramids, and } \\
\text { spheres } \\
\text { Defining } \\
\text { properties of } \\
\text { vertices, edges, } \\
\text { and faces } \\
\text { Describe relative } \\
\text { positions of 3-D } \\
\text { shapes } \\
\text { Make nets and } \\
\text { unfold }\end{array}$ & $\begin{array}{l}\text { Grade } 5 \\
\text { Identify shapes } \\
\text { through counting } \\
\text { Defining properties of } \\
\text { vertices, edges, and } \\
\text { faces } \\
\text { Count the number of } \\
\text { vertices, edges, and } \\
\text { faces } \\
\text { Find laws } \\
\text { Daily life examples } \\
\text { Variation: oblique } \\
\text { prisms/ pyramids, } \\
\text { horizontal } \\
\text { Cuboids/cubes } \\
\text { Make nets and unfold } \\
\text { Understand the } \\
\text { concept of volume } \\
\text { Standard units } \\
\text { Dissecting and fitting } \\
\text { Length } \times \text { width } \times \text { height }\end{array}$ & 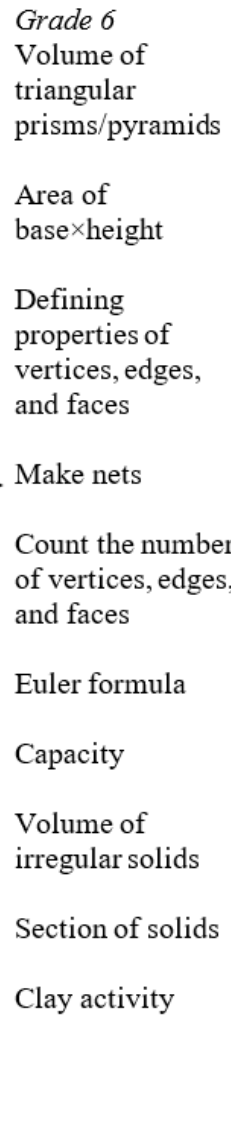 \\
\hline
\end{tabular}

Figure 1. The arrangement of 3-D shapes in Modern Textbooks

taking a closer look at these textbooks, we found some difference in the structure and contents (see Figures 1-3). All the textbooks introduced 3-D shapes at Grade 1. Both
Longman and Modern listed only the contents of the chapters on 3-D shapes in Grade 1, Grade 5 and Grade 6, while Oxford sets some learning objects in Grade 1, 


\begin{tabular}{|c|c|c|}
\hline $\begin{array}{l}\text { Grade 1 } \\
\text { Introduce 3-D } \\
\text { shapes through daily } \\
\text { life examples } \\
\text { Identify shapes } \\
\text { through counting } \\
\text { Focus on prisms, } \\
\text { pyramids, and } \\
\text { spheres }\end{array}$ & $\begin{array}{l}\text { Grade } 5 \\
\text { Base/sides faces } \\
\text { Variation: oblique } \\
\text { prisms/ pyramids, } \\
\text { horizontal } \\
\text { Make nets and unfold } \\
\text { Understand the } \\
\text { concept of volume }\end{array}$ & $\begin{array}{l}\text { Grade } 6 \\
\text { Defining properties } \\
\text { of vertices, edges, } \\
\text { and faces } \\
\text { Count the number of } \\
\text { vertices, edges, and } \\
\text { faces } \\
\text { Make nets and } \\
\text { unfold }\end{array}$ \\
\hline $\begin{array}{l}\text { Count the number of } \\
\text { vertices, edges, and } \\
\text { faces }\end{array}$ & $\begin{array}{l}\text { Cuboids/cubes } \\
\text { Standard units }\end{array}$ & $\begin{array}{l}\text { Section of solids } \\
\text { Capacity }\end{array}$ \\
\hline $\begin{array}{l}\text { Describe relative } \\
\text { positions of } 3-D \\
\text { shapes } \\
\text { Defining properties } \\
\text { of vertices, edges, } \\
\text { and faces }\end{array}$ & $\begin{array}{l}\text { Dissecting and fitting } \\
\text { Length } \times \text { width } \times \text { height } \\
\text { Area of base } \times \text { height } \\
\text { Clay activity }\end{array}$ & $\begin{array}{l}\text { Volume of irregular } \\
\text { solids } \\
\text { Sense of volume }\end{array}$ \\
\hline
\end{tabular}

Figure 2. The arrangement of 3-D shapes in Longman Textbooks

\begin{tabular}{|c|c|c|c|}
\hline $\begin{array}{l}\text { Grade 1 } \\
\text { Introduce 3-D } \\
\text { shapes through } \\
\text { daily life } \\
\text { examples } \\
\text { Characteristics: } \\
\text { shaped size } \\
\text { Focus on prisms, } \\
\text { pyramids, and } \\
\text { spheres } \\
\text { Defining } \\
\text { properties of } \\
\text { vertices, edges, } \\
\text { and faces } \\
\text { Describe relative } \\
\text { positions of 3-D } \\
\text { shapes }\end{array}$ & $\begin{array}{l}\text { Grade } 2 \\
\text { Identify shapes } \\
\text { through } \\
\text { counting } \\
\text { Defining } \\
\text { properties of } \\
\text { vertices, edges, } \\
\text { and faces } \\
\text { Count the } \\
\text { number of } \\
\text { vertices, edges, } \\
\text { and faces }\end{array}$ & $\begin{array}{l}\text { Grade } 5 \\
\text { Make nets } \\
\text { Make } \\
\text { frameworks } \\
\text { Base/sides faces } \\
\text { Cuboids/cubes } \\
\text { Make nets and } \\
\text { Understand the } \\
\text { concept of } \\
\text { volume } \\
\text { Standard units } \\
\text { Dissecting and } \\
\text { fitting } \\
\text { Length } \times \text { width } \times \\
\text { height } \\
\text { Area of } \\
\text { base } \times \text { height }\end{array}$ & $\begin{array}{l}\text { Grade } 6 \\
\text { Make nets } \\
\text { Defining } \\
\text { properties of } \\
\text { vertices, } \\
\text { edges, and } \\
\text { faces } \\
\text { Count the } \\
\text { number of } \\
\text { vertices, } \\
\text { edges, and } \\
\text { faces } \\
\text { Section of } \\
\text { solids } \\
\text { Capacity } \\
\text { Volume of } \\
\text { irregular solids } \\
\text { Clay activity }\end{array}$ \\
\hline
\end{tabular}

Figure 3. The arrangement of 3-D shapes in Oxford Textbooks

Grade 2, Grade 5 and Grade 6. All Grade 5 textbooks showed more content on 3-D shapes, which included making nets and calculating the volume of 3-D shapes. In Grade 6, students would have to understand the concept of capacity and solids. Finding the volume of irregular solids was also a chapter at this stage.

In general, all the textbooks began introducing 3-D shapes with real-life examples to help students to identify these shapes intuitively. Later, on the chapter, some original concepts of 3-D shapes are introduced. For instance: what is a prism and a pyramid? What are the properties and characteristics of these shapes? After these, the textbooks introduce some formulas and laws, including basic units of volume. They then deal with problem solving, including the relationship between different elements of 3-D shapes, finding the volume of solids by different methods, and making nets of 3-D shapes. Appendix 2 provides the summarised learning 


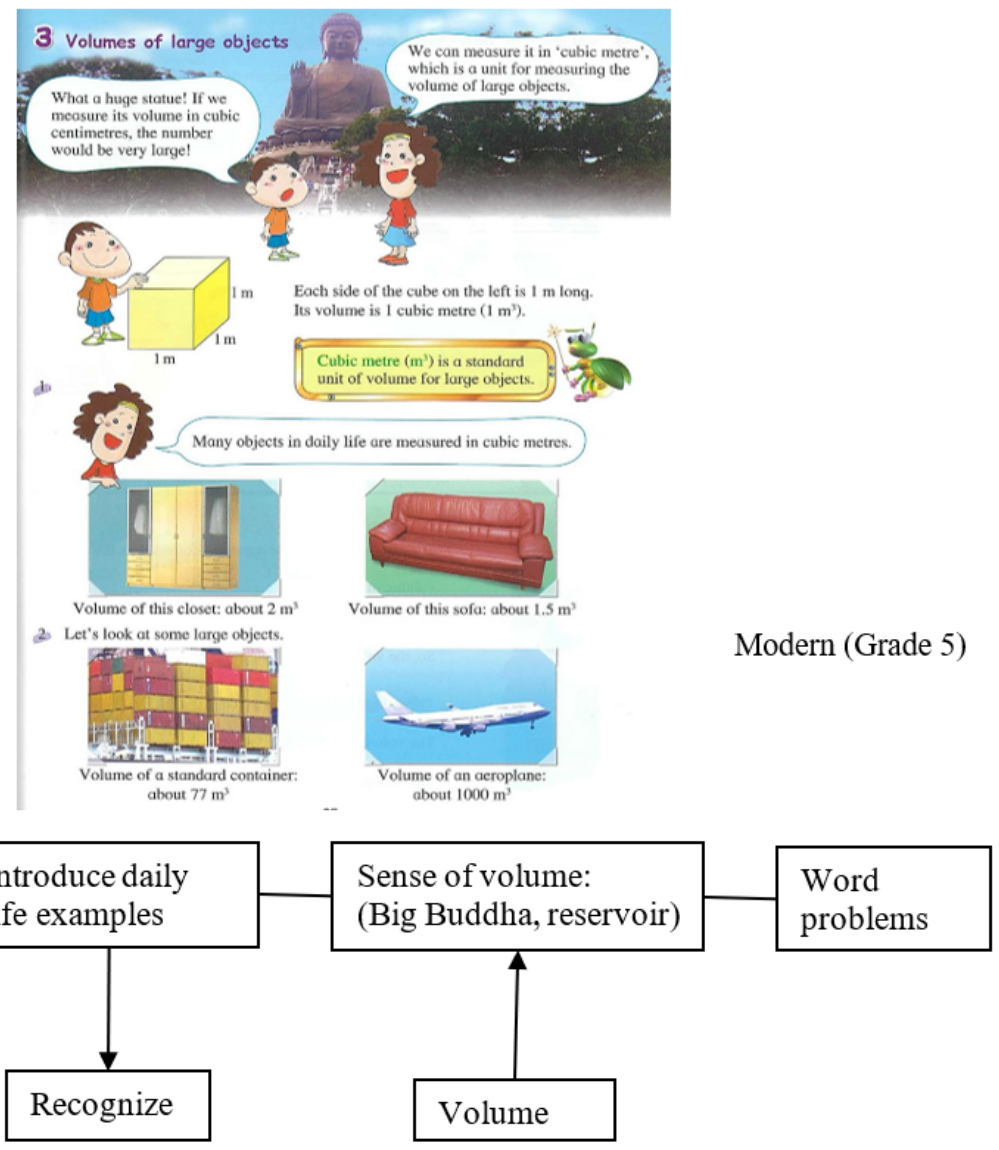

Figure 4. Find 3-D shapes in daily life

trajectory of 3-D shapes in those mathematics textbooks. Our analysis below is based on five components: daily life examples, concepts of 3-D shapes, measures of 3-D shapes, laws of 3-D shapes, and spatial ability.

\section{Daily Life Examples}

Many real-life examples of three-dimensional objects were introduced in the textbooks, such as the camera frame and the top of a pavilion. Students would be required to understand some of the features of threedimensional graphics (e.g., pointy top) by observing these pictures. Besides, the introduction of threedimensional objects in daily life can also help to develop students' sense of volume (such as statues, reservoirs), which is one of the requirements of the new curriculum reform. In particular, Longman textbooks emphasised this aspect. For example, they ask questions such as: (i) what kind of three-dimensional objects are solid or can move; (ii) in order to understand the actual size of $1 \mathrm{~m}^{3}$ and $1 \mathrm{~cm}^{3}$, which is the appropriate unit of measuring such objects; and (iii) how to compare the size of the volume of two objects (see Figure 4).

\section{Understanding Concepts}

To further understand three-dimensional graphics, students need to master learning its features. Classification of objects is an important learning method of understanding concepts. Such methods were found in all three sets of textbooks. This classification is intuitively accessible including observation of the colour, size, thickness, shape, etc. (see Figure 5). Apart from teaching the concept, some non-conceptual comparisons should also be introduced to highlight the essence of the concept. For example, to introduce volume, students should know that this concept has nothing to do with weight; and that the materials and colours are also irrelevant. However, the learning of 3-D objects in the textbooks was narrowed to cylinders, vertebrae and spheres. However, we are in fact exposed to far more types of three-dimensional objects in our daily lives. Indeed, the student's geometric world and learning space is limited to the pictures and graphics printed in the textbooks. A better way perhaps is for teachers to allow students to discover other threedimensional objects in daily life, to enhance their sensitivity to $3-\mathrm{D}$ objects in their surroundings. To further enhance and emphasise the learning of such a concept, teachers can design some extra-curricular activities, such as mathematics adventures.

In this component, students are also required to know the properties of the vertices, edges, and surfaces of three-dimensional objects. The textbooks generally introduced typical three-dimensional objects, such as cubes, cuboids, cylinders, and the vertebral body. These objects were all presented in an upright manner. This kind of orientation may cause misunderstandings in the 


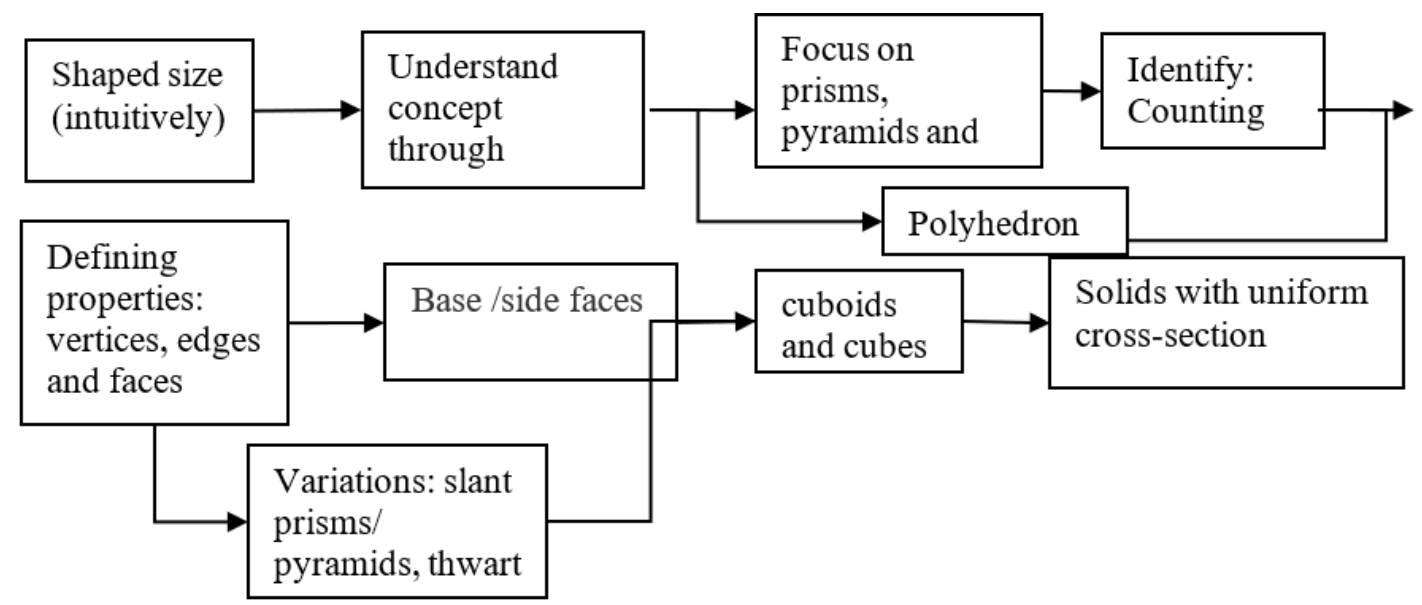

Figure 5. Understand the concept through grouping

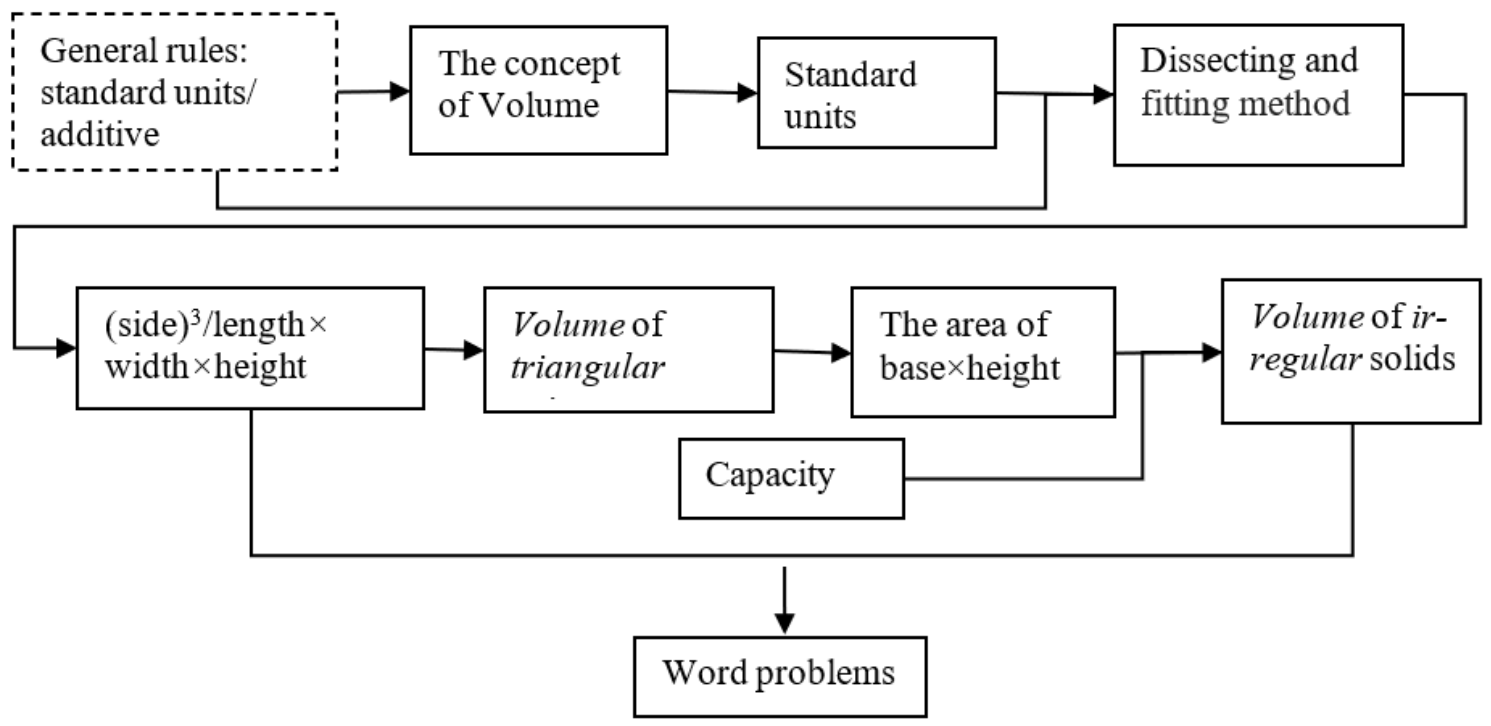

Figure 6. Measure the volume of 3-D shapes

subsequent learning process. The Longman textbook has since made some changes by printing different variations of the cylinder and cone (e.g., oblique cylinder, oblique cone, or to show them horizontally) to expand students' learning space.

\section{Measures of 3-D Shapes}

The metric part of the teaching of 3-D shapes is related to general measure principles, including introducing some basic units and the addition of units. It is also necessary to distinguish volume from the weight, surface area, and capacity. The calculation of threedimensional volume (especially for a rectangular parallelepiped and cube) is mainly taught in this part. Different ways of calculating are also introduced at this stage, including rectangular and cube calculations, triangular prism volume calculations, using the split method and the 'top-up' method to calculate complex three-dimensional volume; and using the drainage method to calculate the irregular three-dimensional volume. Calculation of volume is also reflected in some applications (see Figure 6). These applications help to build on students' sense of volume and space.

In addition, in terms of teaching metrics, these sets of textbooks were mainly confined to the calculating formula and introducing some methods for calculation. However, the textbooks lacked daily life examples. For example, when teachers teach the drainage method, the split method and the 'top-up' method to calculate volume, interesting stories can be used for teaching, which may help to deepen students' impression on the subject.

\section{Laws of 3-D Shapes}

After recognising the important elements of a threedimensional graphic (vertices, edges and faces), the next step is to find implicit rules for these elements. Through counting the number of individual elements, establishing forms and doing comparisons, students would be guided to discover the relationships among them. These are commonly used methods in the textbooks. Many teachers have attached importance to this part, for they commonly regard this section as a 


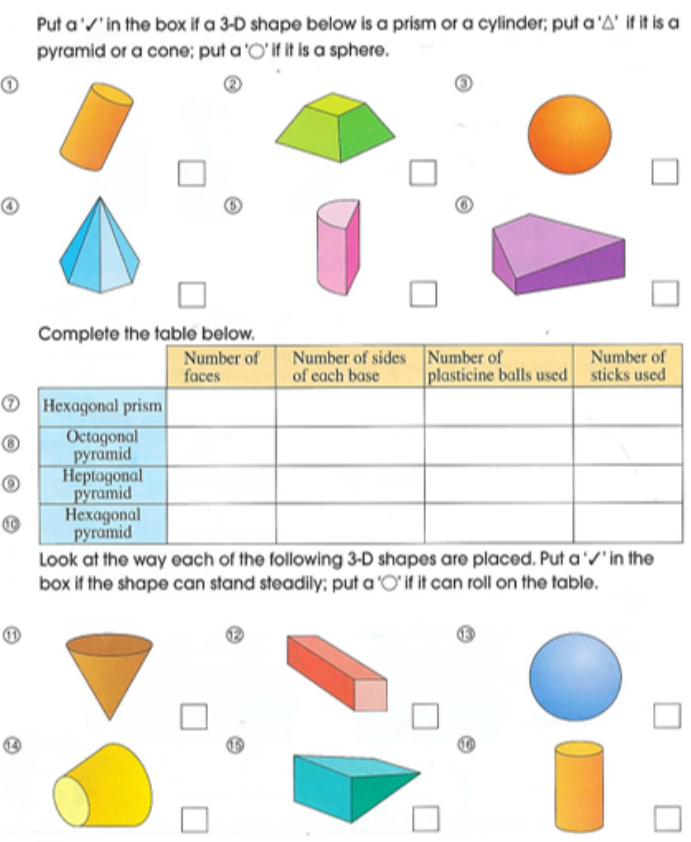

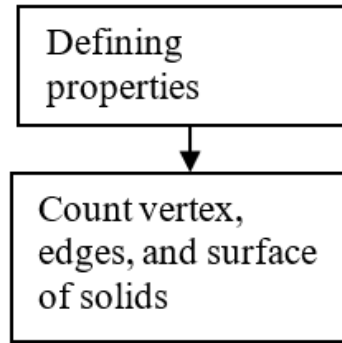

Figure 7. Find the laws of 3-D shapes

focus of geometry. In general, it was found that the teacher would spend more time and effort teaching this section, going into further detail. In fact, according to the course requirements, the relationships between the elements of three-dimensional graphics are not necessarily up to the Euler relation. When students count the number of top edges, faces, etc., they do not expect to get a certain formula. It is very difficult to prove the Euler relation. As such, teachers can introduce extracurricular reading to students (see Figure 7). Indeed, some students may want to discover this relationship voluntarily, particularly through the impact on the counting numbers of other regular polyhedron vertices, edges and faces.

\section{Spatial Ability}

Developing students' spatial ability is the main learning objective and requirement of the subject syllabus. Through understanding this objective, teachers should aim to develop in students the relationship among objects, recognising the inter-dimensional position, and the concept of space. Several sets of textbooks mentioned the use of clay and bracket to create three-dimensional graphics. However, Oxford and Longman listed such activities at Grade 5 and Grade 6. Longman textbook introduced playing with plasticine from Grade 1, which allowed students free play whilst developing spatial awareness of 3 -D objects. In fact, by firstly letting students be free to touch and play with three-dimensional objects, then letting them explore three-dimensional can provide much hands-on experience for children. Dienes (1971) suggested that the formation of mathematical concepts can be constructed in six phases: free to play, games with rules, to find common structure, description or instruction, symbolisation and formalisation. Furthermore, Wong (1990) also pointed out that the establishment of the spatial cognitive ability can also be explained using the six-stage theory. He further described it as contact and free play, three-dimensional math games, using threedimensional model to understand spatial relationships, making dimensional model by hand, handling threedimensional problems from the plan deal, and without drawing but from the context to tackle a threedimensional problem. Through hands-on activities, students can constantly try to explore the laws before using the strategies for problem solving. 

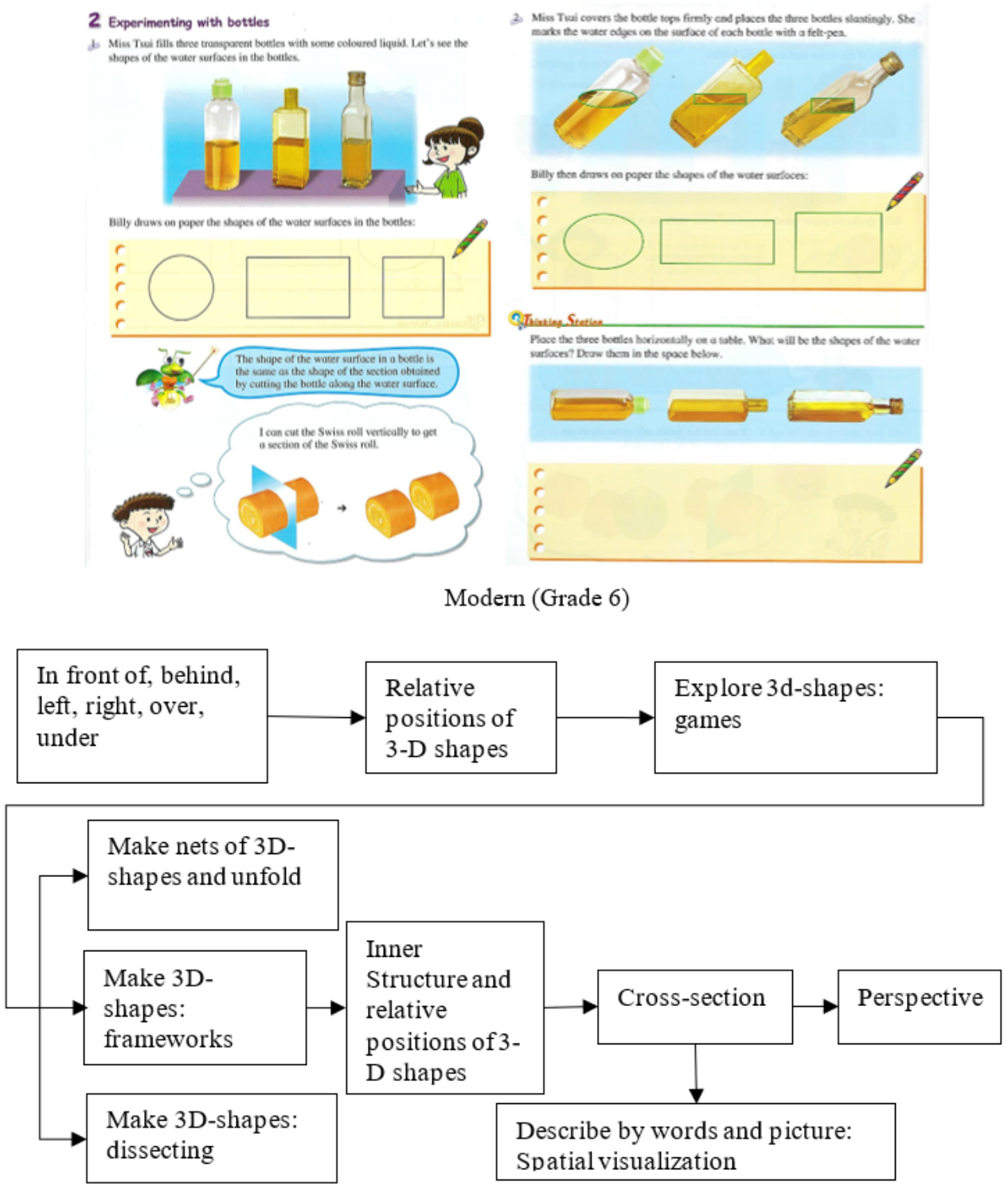

Figure 8. Develop spatial ability through activities

Cutting three-dimensional graphics and understanding the inner structure of three-dimensional graphics have already been involved in some high-level capabilities. Courses containing them are mainly due to the impact of earlier spatial tests. At the elementary level, students' experiences are more important, and these experiences can contribute to learning calculations but not necessarily restricted to a paper-based test. For example, when introducing the section, bottles with oil are useful. Whether the bottles are upright or tilted, students can see the oil level and cross-section clearly and dynamically (see Figure 8).

\section{CONCLUSION}

Numerous studies have shown that there is a strong correlation between the content that is taught and the achievements of the students in the school (Cueto, Ramírez, \& León, 2006; Haggarty \& Pepin, 2002; Törnroos, 2005; Wijaya, van Den Heuvel-Panhuizen, \&
Doorman, 2015). The generative concept behind this correlation is the opportunities to learn, which was described as "whether or not ... student has had the opportunity to study a particular topic or learn how to solve a particular type of problem" (Husen, 1967, p. 162163). Using the content-analysis method, we examined three local mathematics textbooks in Hong Kong focusing on the topic of 3-D graphics, to see the if textbooks provide enough opportunities to students to learn spatial geometry, and how the contents are arranged in textbooks to promote students' learning.

In order to enrich students' learning in 3-D shapes, the contents in all three textbooks were designed to relate to five areas. These included introducing real-life examples, recognising geometric concepts, measuring operations, finding laws and developing spatial ability. These five areas are also closely related to students' geometric thinking levels (van Hiele, 1986). Even though these five aspects coincide with the objectives of the Hong Kong mathematics curriculum, the three 
textbooks had their individual way of presenting the topic. The subject was generally taught to students in Grade 1, Grade 5 and Grade 6. However, Longman also published the 3-D geometry topic in their Grade 2 textbooks. Generally, it was found that students in lower grades focused mainly on three-dimensional visual experience. Upper grade students started to learn some calculations (shown with counting the number of vertices, edges and faces, calculating the volume), and spatial abilities are mainly shown in the production of three-dimensional graphics penetration activities.

From the results of the analysis, we can see that the learning content of 3-D geometry is hardly found in primary school textbooks and there is little content involving calculation. In other words, these textbooks have attached much more importance to the experience of exploring three-dimensional graphics. Nonetheless, there was insufficient content pertaining to this aspect in the textbooks and, where they do appear, were mainly found in higher grade textbooks. Kan et al. $(1995,1996)$ had similar findings in their early studies on Hong Kong primary school textbooks. They found that textbooks often neglected basic and specific activities to help develop students' spatial sense, and appear to be replaced by some written exercises. It is a common Chinese saying that 'hard work is useful while play is useless'. In fact, mathematics games and hands-on activities are not waste of time in classroom. They include rich learning elements and can help students to develop problem-solving abilities and higher-order thinking skills (Ping \& Hua, 2016).

It was also found that from the textbook analysis, what students experienced in the learning of 3-D geometry at school might be relatively narrow. Geometry graphics were mainly limited to the conventional rectangular, cube, pyramid or cone, and column with upright placement at the early stage, which all appeared to lack changes of shape. Kan et al. (1995, 1996) also mentioned that textbooks tended to use many typical examples but neglected that these might lead to misunderstandings and misinterpretations for students. Within these sets of textbooks, the development of spatial ability in looking for patterns also tended to only achieve numerical relationships among geometric elements but neglected the interaction between students and concrete objects. The requirements on students' capacity were too high and too deep, even for the purposes of commencing high school. These findings were also similar to Hsu's series of comparative studies (Hsu \& Lin, 2008, 2009). They compared mathematics textbooks of Hong Kong and Taiwan primary schools and found that the textbooks in Hong Kong contained a deeper and wider range of content than those of Taiwan's. The reason may be that teachers or textbooks have not fully realised the impact and value of the experience of exploring three-dimensional objects on children's spatial ability.
Referring to geometry teaching, Bishop (1983) ever proposed the point that teachers need to take more advantage of the existed space environment, which can be used for children to learn geometry and develop their spatial ability. As the main learning material, the contents of textbooks need to list and create more activities for students, and teachers' teaching should be flexible to accommodate such activities. Therefore, it is worth studying the influence of different spatial environments on children's understanding of geometric concepts and their spatial sense. Despite the dominant role that mathematics textbooks have historically played in defining the school mathematics experience of students, drawing a direct link from textbooks to student learning is difficult because many other factors influence what students learn, including teacher choices and actions, school and classroom organisation, and students' readiness and willingness to learn (Tarr et al., 2008). Rezat (2009) described a triangular relationship between textbooks, teachers and students: The mathematics textbook is implemented as an instrument on all three sides of the triangle: teachers use textbooks in the lesson and to prepare for their lessons; by using textbooks in the lessons, teachers also mediate textbook use to students; and finally, students learn from textbooks (p. 1261). However, teachers' adoption of textbooks all varied. There existed gaps between the illustrations in the textbooks and teachers' explanations of such illustrations. According to the framework in TIMSS, students' attained curriculum shall also be considered when we examine the learning opportunities. The user experience of students and teachers can all be investigated in the future.

Author contributions: All authors have sufficiently contributed to the study, and agreed with the results and conclusions.

Funding: The study received partial financial support from the Education University of Hong Kong 2020 Dean's Research Fund and MIT Departmental Collaborative Fund 2019-20.

Declaration of interest: No conflict of interest is declared by authors.

\section{REFERENCES}

Abdullah, A., Ahmad, N., \& Nohseth, N. (2020). Investigating student's learning difficulties in Shape and Space topic: A case study. International Journal of Psychosocial Rehabilitation, 24(5), 53155321.

https:/ / doi.org/10.37200/IJPR/V24I5/PR2020238

Alajmi, A. H. (2012). How do elementary textbooks address fractions? A review of mathematics textbooks in the USA, Japan, and Kuwait. Educational Studies in Mathematics, 79(2), 239-261. https: / / doi.org/10.1007/s10649-011-9342-1

Bishop, A. J. (1983). Space and geometry. In R. Lesh \& M. Landau (Eds.), Acquisition of mathematics concepts and processes (pp. 125-203). Academic Press. 
Carter, J., Li, Y., \& Ferrucci, B. (1997). A comparison of how textbooks present integer addition and subtraction in China and the United States. The Mathematics Educator, 2(2), 197-209.

Charalambous, C., Delaney, S., Hsu, H., \& Mesa, M. (2010). A Comparative analysis of the addition and subtraction of fractions in textbooks from three countries. Mathematical Thinking and Learning: An International Journal, 12(2), 117-151. https:/ / doi.org/10.1080/10986060903460070

Clements, D., \& Battista, M. (1992). Geometry and spatial reasoning. In D. A. Grouws (Ed.), Handbook of Research on Mathematics Teaching and Learning-A project of the National Council of Teachers of Mathematics. Macmillan Publishing Company.

Cueto, S., Ramírez, C. \& León, J. (2006). Opportunities to learn and achievement in mathematics in a sample of sixth grade students in Lima, Peru. Educational Studies in Mathematics, 62(1), 25-55. https: / / doi.org/10.1007/s10649-006-7922-2

Curriculum Development Council. (2000). Learning to learn: The way forward in curriculum development consultation document. The Council.

Curriculum Development Council. (2002). Basic education curriculum guide: Building on strengths. The Council.

Dienes, Z. P. (1971). Building up Mathematics (4th Ed.). Hutchinson.

Fan, L., \& Zhu, Y. (2007). Representation of problemsolving procedures: A comparative look at China, Singapore, and US mathematics textbooks. Educational Studies in Mathematics, 66(1), 61-75. https: / / doi.org/10.1007/s10649-006-9069-6

Flores-Bascuñana, M., Diago, P. D., Villena-Taranilla, R., \& Yáñez, D. F. (2020). On augmented reality for the learning of 3D-geometric contents: A preliminary exploratory study with 6-grade primary students. Education Sciences, 10(1), 4. https://doi.org/ 10.3390/educsci10010004

Haggarty, L., \& Pepin, B. (2002). An investigation of mathematics textbooks and their use in English, French, and German Classrooms: Who gets an opportunity to learn what? British Educational Research Journal, 28(4), 567-590. https://doi.org/ $10.1080 / 0141192022000005832$

Hallowell, D. A., Okamoto, Y., Romo, L. F., \& La Joy, J. R. (2015). First-graders' spatial-mathematical reasoning about plane and solid shapes and their representations. ZDM: The International Journal of Mathematics Education, 47(3), 363-375. https: / / doi.org/10.1007/s11858-015-0664-9

Ho, S. C. (Ed.). (2011). The fourth HKPISA report PISA 2009: Monitoring the quality and equality of education in Hong Kong from an international perspective from
PISA 2000 to PISA 2009. HKPISA Centre, The Chinese University of Hong Kong.

Hus, W. M., \& Lin, M. J. (2008). A content analysis of geometry material in elementary school textbook of Taiwan and Hong Kong. Journal of National Pingtung University of Education, 28, 1-52.

Hus, W. M., \& Lin, M. J. (2009). A content analysis of geometry materials in elementary mathematics textbook of Taiwan, China and Hong Kong. National Changhua Educational journal, 16, 49-75.

Jones, D. L., \& Tarr, J. E. (2007). An examination of the levels of cognitive demand required by probability tasks in middle grades mathematics textbooks. Statistics Education Research Journal, 6(2), 4-27.

Kan, P. W., Ma, S. Y., So, W. Y., \& Wong, K. M. (1995). An analysis of the Hong Kong primary mathematics textbooks: The learning dimension of shape and space (1). EduMath, 1, 16-18.

Kan, P. W., Ma, S. Y., So, W. Y., \& Wong, K. M. (1996). An analysis of the Hong Kong primary mathematics textbooks: The learning dimension of shape and space (2). EduMath, 2, 39-45.

Kolovou, A, van den Heuvel-Panhuizen, M. \& Bakker, A. (2009). Non-routine problem solving tasks in primary school mathematics textbooks: A needle in a haystack. Mediterranean Journal for Research in Mathematics Education, 8(2), 31-68.

Krippendorff, K. (1980). Content analysis: An introduction to its methodology. Sage.

Lohman, D. F. (1988). Spatial abilities as traits, processes, and knowledge. In R. J. Sternberg (Ed.), Advances in the psychology of human intelligence (Vol. 40, pp. 181248). Erlbaum.

Mesa, V. (2004). Characterizing practices associated with functions in middle school textbooks. Educational Studies in Mathematics, 56, 255-286. https:/ / doi.org /10.1023/B:EDUC.0000040409.63571.56

Mullis, I. V. S., Martin, M. O., \& Foy, P. (2008). TIMSS 2007 international mathematics report: Findings from IEA's Trends in International Mathematics and Science Study at the eighth and fourth Grades. Boston College.

Mullis, I.V.S., Martin, M.O., Foy, P., \& Arora, A. (2012). TIMSS 2011 international results in mathematics. Boston College.

Ng, O., Shi, L., \& Ting, F. (2020). Exploring differences in primary students' geometry learning outcomes in two technology-enhanced environments: Dynamic geometry and 3D Printing. International Journal of STEM Education. https://doi.org/10.1186/s40594020-00244-1

OECD (2014). PISA 2012 results: What students know and can do (Volume I). OECD. https:/ / www.oecd.org/ pisa/keyfindings/pisa-2012-results-volume-I.pdf 
OECD (2019). PISA 2018 Assessment and Analytical Framework. OECD Publishing. https://doi.org/ 10.1787/b25efab8-en

Ozdemir, G. (2010). Exploring visuospatial thinking in learning about mineralogy: spatial orientation ability and spatial visualization ability. International Journal of Science and Mathematics Education, 8(4), 737-759. $\quad$ https://doi.org/10.1007/s10763-0099183-x

Ping, O. W., \& Hua, A. K. (2016). A case report of educational in 3D and 2D towards primary mathematics. Asia Pacific Journal of Education, Arts and Science, 3(2), 8-12. https://doi.org/10.6084/ m9.figshare.3398614.v1

Pingel, F. (1999). UNESCO guidebook on textbook research and textbook revision. Hahn.

Reys, B., Reys, R., \& Koyama, M. (1996). The development of computation in three Japanese primary-grade textbooks. The Elementary School Journal, 96(4), 423-437. https://doi.org/10.1086/ 461837

Reys, R., Reys, B., Lapan, R., Holliday, G., \& Wasman, D. (2003). Assessing the impact of standards-based middle grades mathematics curriculum materials on student achievement. Journal for Research in Mathematics Education, 34(1), 74-95. https:/ / doi.org/10.2307/30034700

Rezat, S. (2009). The utilization of mathematics textbooks as instruments for learning. In V. Durand-Guerrier, S. Soury-Lavergne, \& F. Arzarello (Eds.), Proceedings of CERME6 (Vol 6, pp. 1260-1269), Lyon France.

Stein, M., Remillard, J., \& Smith, M. (2007). How curriculum influences students' learning. In F. Lester (Ed.), Second handbook of research on mathematics teaching and learning (pp. 557-628). Information Age.

Strauss, A., \& Corbin, J. M. (1990). Basics of qualitative research: Grounded theory procedures and techniques. Sage Publications, Inc.

Sun, X. (2011). Variation problems and their roles in the topic of fraction division in Chinese Mathematics textbook examples. Educational Studies in
Mathematics, 76(1), 65-85. https://doi.org/10.1007/ s10649-010-9263-4

Tarr, J. E., Reys, R. E., Reys, B. J., Chavez, O., Shih, J., \& Osterlind, S. J. (2008). The impact of middle-grades mathematics curricula and the classroom learning environment on student achievement. Journal for Research in Mathematics Education, 39(3), 247-280. https://www.jstor.org/stable/30034970

Törnroos, J. (2005). Mathematics textbooks, opportunity to learn and student achievement. Studies in Educational Evaluation, 31(4), 315-327. https: / / doi.org/10.1016/j.stueduc.2005.11.005

Van Hiele, P. M. (1986). Structure and insight. A theory of mathematics education. Academic press Inc.

Vincent, J., \& K. Stacey (2008). Do mathematics textbooks cultivate shallow teaching? Applying the TIMSS Video Study criteria to Australian Eighth-grade mathematics textbooks. Mathematics Education Research Journal. 20(1), 82-107. https://doi.org/ 10.1007/BF03217470

Wai, J., Lubinski, D., \& Benbow, C. P. (2009). Spatial ability for STEM domains: Aligning over fifty years of cumulative psychological knowledge solidifies its importance. Journal of Educational Psychology, 101, 817-835. https:/ / doi.org/10.1037/a0016127

Wijaya, A., van Den Heuvel-Panhuizen, M., \& Doorman, M. (2015). Opportunity-to-learn context-based tasks provided by mathematics textbooks. Educational Studies in Mathematics, 89(1), 41-65. https:/ / doi.org/10.1007/s10649-015-9595-1

Wong, K. L. (2014). Mathematical literacy. In S. C. Ho (Ed.), The fifth HKPISA report: PISA2012 (pp. 45-93). The Chinese University of Hong Kong, Hong Kong: Hong Kong PISA Centre.

Wong, N. Y. (1990). Spatial mathematical games and the training of spatial ability [in Chinese]. Math Media, $56,78-96$.

Wong, N. Y., Han, J. W., \& Lee, P. Y. (2004). The mathematics curriculum: Towards globalisation or Westernisation? In L. Fan, N. Y. Wong, J. Cai, \& S. Li (Eds.), How Chinese learn mathematics: Perspectives from insiders (pp. 27-70). World Scientific. https://doi.org/10.1142/9789812562241_0002 


\section{APPENDIX 1}

\section{Examples on the Organization of Unites in Spatial Geometry in Primary Curriculum}

\begin{tabular}{|c|c|}
\hline Learning Unites & Suggested Learning Objectives \\
\hline \multirow{7}{*}{$\begin{array}{l}\text { 1S1 3-D shapes (I) } \\
\text { (prisms, pyramids and spheres) }\end{array}$} & 1. Recognize prisms, pyramids and spheres. \\
\hline & 2. Identity 3-D shapes intuitively. \\
\hline & 3. Group 3-D shapes. \\
\hline & 4. Describe the relative positions of two 3-D shapes briefly. \\
\hline & Remarks: \\
\hline & $\begin{array}{l}\text { 1. Group 3-D shapes according to shape, size, colour, thickness, hardness or other } \\
\text { properties. }\end{array}$ \\
\hline & $\begin{array}{l}\text { 2. Describe the relative positions of two 3-D shapes using 'in front of','behind','left', } \\
\text { 'right','over' or 'under'. }\end{array}$ \\
\hline \multirow{5}{*}{$\begin{array}{l}\text { 2S1 3-D shapes (II) } \\
\text { (prisms, cylinders, pyramids } \\
\text { and cones) }\end{array}$} & 1. Identify prisms and cylinders intuitively. \\
\hline & 2. Identify pyramids and cones intuitively. \\
\hline & 3. Recognize faces intuitively. \\
\hline & 4. Group 3-D shapes. \\
\hline & 5. Make 3-D shapes. \\
\hline \multirow{2}{*}{$\begin{array}{l}\text { 5S2 3-D shapes (III) } \\
\text { (characteristics of prisms, } \\
\text { pyramids and spheres) }\end{array}$} & 1. Recognize the characteristics of cones, pyramids, cylinders, prisms and spheres. \\
\hline & 2. Make nets of cubes and cuboids \\
\hline \multirow[t]{7}{*}{ 5M2 Volume (I) } & 1. Develop the concept of volume. \\
\hline & 2. Compare the volume of objects intuitively. \\
\hline & 3. Introduce the standard unit 'cubic centimetre' $\left(\mathrm{cm}^{3}\right)$. \\
\hline & 4. Measure and compare the volume of objects using 'cubic centimetre'. \\
\hline & 5. Understand the need for using a unit larger than 'cubic centimetre'. \\
\hline & 6. Introduce 'cubic metre' $\left(\mathrm{m}^{3}\right)$ \\
\hline & 7. Understand and apply the formulae for finding the volume of cubes and cuboids. \\
\hline \multirow{6}{*}{$\begin{array}{l}\text { 6S1 3-D shapes (IV) (vertices, } \\
\text { edges, faces and sections) }\end{array}$} & 1. Recognize the vertices, edges and faces of 3-D shapes. \\
\hline & 2. Make frameworks of prisms and pyramids. \\
\hline & $\begin{array}{l}\text { 3. Explore the relationship between the number of edges and the number of sides of the } \\
\text { bases of prisms and pyramids. }\end{array}$ \\
\hline & $\begin{array}{l}\text { 4. Explore the relationship between the number of vertices and the number of sides of } \\
\text { the bases of prisms and pyramids. }\end{array}$ \\
\hline & 5. Explore and design nets of prisms. \\
\hline & 6. Make pyramids and prisms. \\
\hline 6M1 & 1. Recognize the relationship between capacity and volume. \\
\hline Volume (II) & 2. Find the volume of irregular solids by displacement of water. \\
\hline Enrichment Topics & Suggested Learning Objectives \\
\hline \multirow[t]{2}{*}{ 6S-E2 Making pyramids } & 1. Explore and design nets of pyramids. \\
\hline & 2. Make pyramids. \\
\hline
\end{tabular}


APPENDIX 2

Learning Trajectory of 3-D Shapes in Primary Mathematics

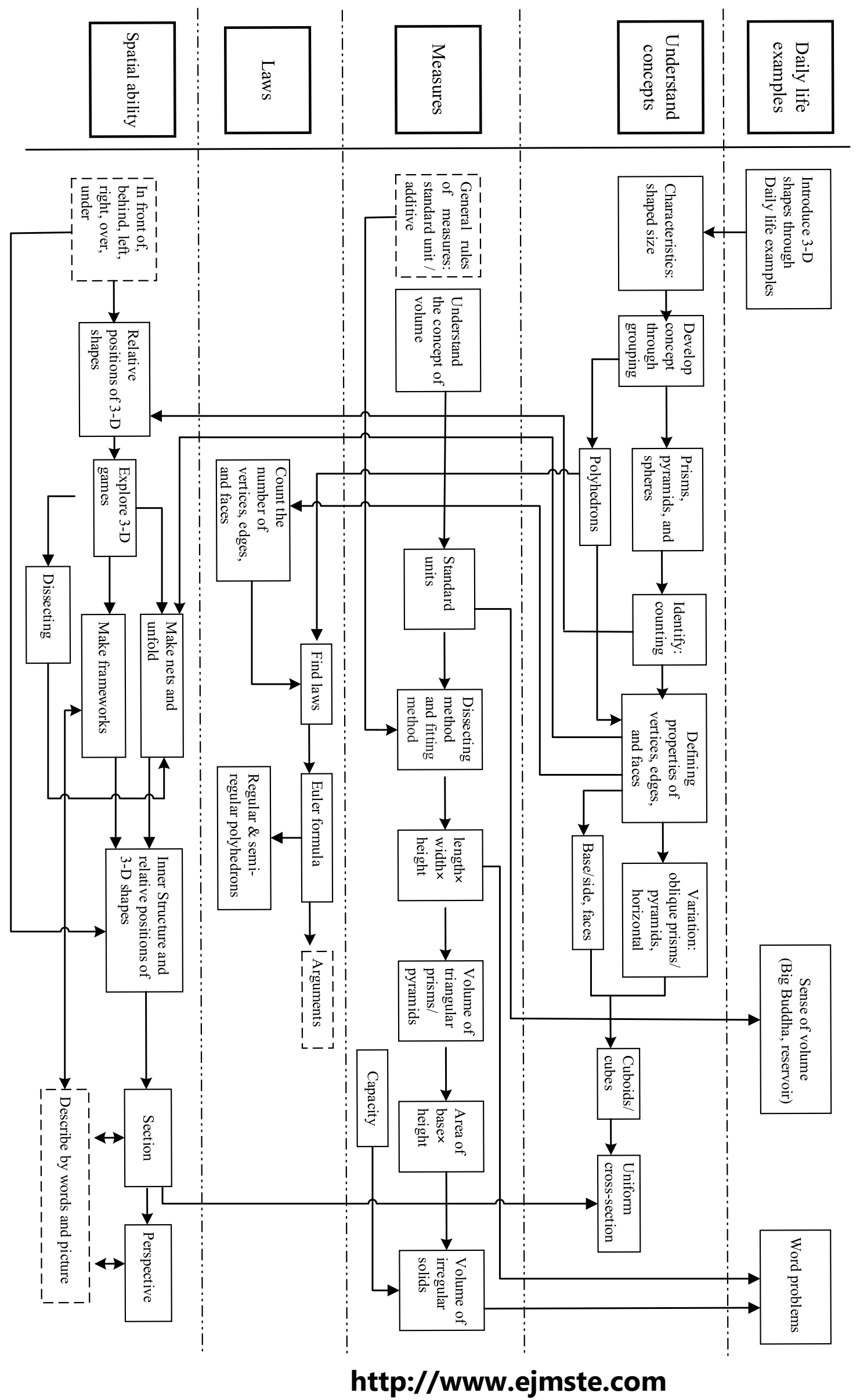

